\title{
Cardiovascular Neoplasm
}

National Cancer Institute

\section{Source}

National Cancer Institute. Cardiovascular Neoplasm. NCI Thesaurus. Code C4784.

A benign or malignant neoplasm that affects the heart and/or vessels. Representative

examples of benign neoplasms include atrial myxoma, hemangioma, and lymphangioma.

Representative examples of malignant neoplasms include pericardial malignant mesothelioma and angiosarcoma. 